\title{
Post traumatic biparietal mirror Extradural haematoma - a case report and review of literature
}

\author{
G. Venkateswara Prasanna ${ }^{1}$, Sathish Kumar Vandanapu ${ }^{2}$, Hima Bindu ${ }^{3}$ \\ ${ }^{1,2}$ consultant Neurosurgeon, ${ }^{3}$ consultant Radiologist \\ Simhapuri Institute of Neurological Sciences, Simhapuri Hospital, Nellore, Andhra Pradesh, INDIA
}

\begin{abstract}
Bilateral extradural haematomas [EDH] are rare and it is an uncommon consequense of cranio cerebral trauma. The mortality is higher than unilateral extradural haematoma and management of extradural haematomas requires careful planning, judicial surgical exposure and most important is timing of evacuation of extradural haematomas. Emergency evacuation of bilateral extradural haematomas were performed in this case with uneventful postoperative period. The pathophysiology and surgical nuances of this rare entity been discussed.
\end{abstract}

Key words: Extradural haematoma, biparietal, symmetric

\section{Introduction}

Biparietal mirror Extradural haematoma is extremely rare with only a handful of cases reported in literature..$^{1,2,8,9,12}$ Incidence of bilateral EDH ranges from 2 to $25 \%{ }^{3}$ Bifrontal EDH is most common among bilateral EDH. Biparietal mirror Extradural haematoma is a rare entity. Emergency evacuation of bilateral extradural haematomas with bilateral craniotomies is the treatment of choice. Biparietal Extradural haematoma is associated with low GCS and associated with higher mortality than solitary EDH if not timely interfered. Authors report a case, who had low GCS on admission, been subjected to emergency bilateral craniotomies with uneventful postoperative period, with good outcome.

\section{Case report}

A 25- year-old male was brought to our emergency department, 24 hours following a motor vehicle accident. Initially treated in a local hospital, been referred following neurological deterioration. History of loss of consciousness is present. History of multiple episodes of vomiting is present. On assessment, he had a GCS of 5/15 for which he was intubated. Pupils were asymmetric with sluggish reaction to light. Examination of scalp suggestive of diffuse subgaleal hamaetoma. His Computed tomography (CT) scan brain showed a symmetrical biparietal EDH with bilateral parietal linear fractures. Emergency evacuation of bilateral Extradural haematoma was done. With the patient in prone bilateral 
horse shoe scalp flaps over the parietal eminences were raised. Bilateral parietal craniotomies were done and haematoma evacuation was done. Arterial bleeders were identified and coagulated. Dural hitches were taken. Complete haemostasis been achieved.

\section{Discussion}

Contact injuries resulting from blunt trauma cranium results in EDH. Extradural haematoma is the most common manifestation of traumatic brain injury. Roy in 1884 reported the first case of bilateral EDH. The incidence of bilateral EDH ranges from 225\%. ${ }^{3,7}$ Of these bilateral EDHs bilateral frontal $\mathrm{EDH}$ is the most common. ${ }^{7}$ Male to female ratio is $5: 1{ }^{12}$ Very few cases of symmetric bilateral EDH were reported in literature. ${ }^{1,8,9,12}$

Various theories were postulated for bilateral injuries, the impact tend to be on anteroposterior direction rather than lateral direction. ${ }^{4}$ Dura is detached from two sites by a unidirectional force. Stripping of dura can ocuur at the site of impact by inbending or outbending of skull or due to motion of skull.
Bilateral parietal bone flaps were replaced. Post-operative scan showed no residual haematoma. Post-operative period was uneventful. He made a gradual recovery and was discharged on $10^{\text {th }}$ postoperative period in good condition, with GCS of 15/15.

It can be due to extension of fracture line across midline, which is most commonly seen in bifrontal and bilateral posterior fossa EDH. ${ }^{9}$ Coup and countra coup injuries to the skull can also cause bilateral EDH. ${ }^{11}$ Bilateral EDHs are different from solitary EDH. They are associated with significant trauma, evolve rapidly, and are associated with high mortality. ${ }^{6,7}$ Patients with bilateral EDHs less frequently have a lucid interval, have a lower GCS, lateralization is frequently absent, and deteriorate more frequently than individuals with unilateral EDH., ${ }^{4,8,10}$ One entity similar to bilateral EDH is the double EDH. In double $\mathrm{EDH}, \mathrm{EDH}$ is found in two locations irrespective of laterality and symmtricity. ${ }^{7}$ In this case we report bilateral symmetric biparietal EDH, were only few cases have been reported. Table 1 summarizes the reported cases.

TABLE 1

Literature review on traumatic symmetric biparietal extradural hematomas

\begin{tabular}{|l|c|c|c|c|c|c|}
\hline Author & No of cases & Age/Sex & $\begin{array}{c}\text { Mode of } \\
\text { injury }\end{array}$ & GCS & Treatment & $\begin{array}{c}\text { Final } \\
\text { outcome } \\
\text { (GCS) }\end{array}$ \\
\hline Idei et al $^{1}$ & 1 & $72 / \mathrm{M}$ & Fall & NA & Surgery B/L & Good (15) \\
\hline Ramzan et al $^{2}$ & 2 & NA & NA & 14 & $\begin{array}{c}\text { Surgery B/L } \\
\text { Surgery B/L }\end{array}$ & $\begin{array}{c}\text { Good(15) } \\
\text { Fair(12) }\end{array}$ \\
\hline Udoh et al $^{3}$ & 2 & $64 / \mathrm{M}$ & RTA & 11 & $\begin{array}{c}\text { Left-surgery; } \\
\text { right-resolved }\end{array}$ & Good(15) \\
\hline
\end{tabular}




\begin{tabular}{|l|c|c|c|c|c|c|}
\hline & & $60 / \mathrm{M}$ & RTA & 7 & Surgery B/L & Died \\
\hline Agrawal et al $^{4}$ & 1 & $55 / \mathrm{F}$ & Fall of object & 9 & Surgery B/L & Good(15) \\
\hline Prasad et al $^{13}$ & 2 & $60 / \mathrm{M}$ & RTA & 4 & Surgery B/L & Good(15) \\
& & $30 / \mathrm{M}$ & RTA & 7 & SurgeryB/L & Good(15) \\
\hline $\begin{array}{l}\text { Prasanna et al } \\
\text { (Present) }\end{array}$ & 1 & $25 / \mathrm{M}$ & RTA & 5 & Surgery B/L & Good(15) \\
\hline
\end{tabular}

Abbreviations- GCS -Glasgow coma scale; B/L-Bilateral; NA-Not available; RTA- Road traffic accident

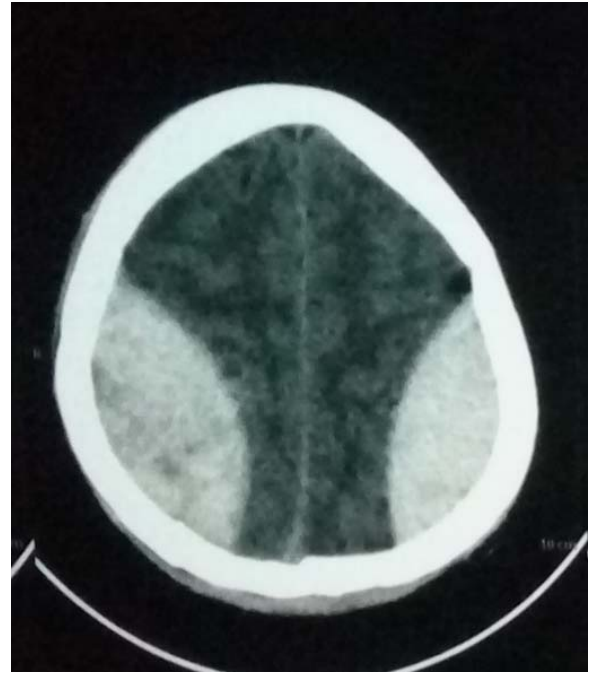

Figure 1 - Plain CT Brain showing Bi parietal EDH

EDHs secondary to blunt trauma with skull bone fractures, the fracture detaches the dura and injures blood vessels, once bleeding begins the extradural space is filled with blood. Arterial bleeding produces hydrostatic water pressure, leading to stripping away of dura from the skull and widening the perimeter of the haematoma. Venous bleeding is slower, tends to be smaller in size and less severe due to ease of spontaneous arrest. ${ }^{12}$ In this case cause of biparietal EDHs is linear skull fractures injuring the arterial vessels which were coagulated during haematoma evacuation.

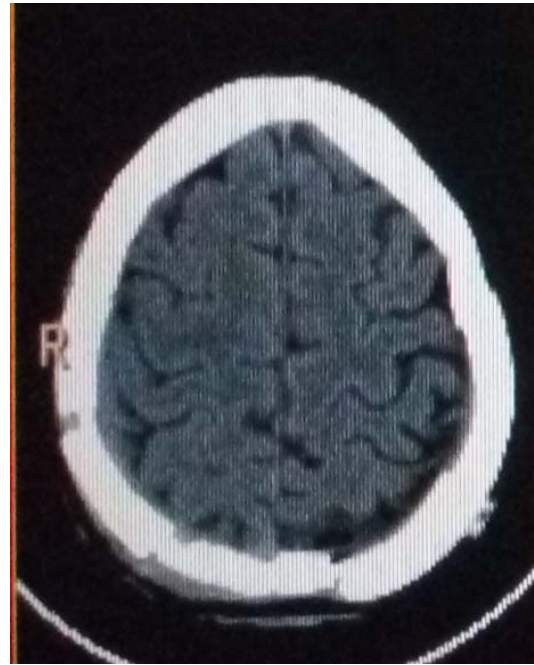

Figure 2 - Post-operative image showing Bi parietal craniotomies with complete evacuation of haematomas

Surgical evacuation of haematoma should be done on emergency basis. Side of surgery depends on volume of hematoma. It has been suggested that with similar volumes bilaterally, craniotomy and evacuation need to be performed on both sides, initially on dominant side or simultaneously by two groups of neurosurgeons. ${ }^{1,3,8}$ Agrawal suggested use of bicoronal skin flap, performing of craniotomies on both sides and then evacuation of hematoma sequenitially. ${ }^{1}$ In our case, patient is placed in prone position bilateral horse shoe scalp incisions centered on 
the parietal eminences were taken. Scalp flaps been elevated. Craniotomy done initially on dominant side followed by non-dominant side. Haematoma evacuation was done. Arterial bleeders were coagulated, dural hitches taken. Complete haemostasis been achieved. Bone flaps were replaced. Drains were put on both sides before closing of the scalp flaps. On first post-operative period drains were removed. Post-operative CT brain showed complete evacuation of haematoma.

\section{Conclusion}

Symmetric biparietal EDHs are rare and carry high mortality when compared with solitary EDH. Emergency evacuation of haematomas should be done. Good intensive care is needed post operatively, as these are severe traumatic head injuries. Timing of haematoma evacuation is important for good outcome.

\section{Correspondence}

Dr. Sathish Kumar Vandanapu

Simhapuri Institute of Neurological Sciences Simhapuri Hospital, Chinthareddypalem Nellore524003 Andhra Pradesh (India)

Email-sathishvandanapu@gmail.com

Mobile- +91-8008222342

\section{References}

1. Agrawal A.Bilateral Symmetrical Parietal Extradural Hematoma.J Surg Tech Case Rep2011;3:34-36.

2. Cirak B, Mut M, Akalan N. Bilateral epidural hematoma in a pyknodysostotic child. Pediatric Neurosurg 1999; 30: 33-34

3. Dharker SR, Bhargava N. Bilateral epidural haematoma. Acta Neurochir (Wien) 1991; 110: 29-32

4. Frank E, Berger TS, Jew JM. Bilateral epidural hematoma. Surg Neurol 1982;17:218-22

5. G.Lakshmi Prasad, Sumit sinha et al.Traumatic symmetric biparietal extradural haematoma: Report

of two cases.Neurological surgeon's society of india 2016

6. Gorgulu A, Cobanoglu S, Armagan S, Karabagli H, Tevruz M. Bilateral epidural hematoma. Neurosurg Rev 2000;23:30-3

7. Huda MF, Mohanty S, Sharma V, Tiwari Y, Choudhary A, Singh VP. Double extradural hematoma: An analysis of 46 cases. Neurol India 2004; 52: 450-452

8. Idei M, Shima T, Nishida M, Yamanae K, Mihara C, Hatayama $\mathrm{T}$, Onda $\mathrm{H}$, et al. Symmetrical bilateral epidural hematoma after head injury in the mid parietooccipital region: Case report. No Shinkei Geka 2004; 32: 379-382

9. Ramzan A, Wani A, Malik AH, Kirmani A, Wani MA. Acute bilateral extradural hematomas. Neurol India 2002; 5: $217-218$

10. Rasmussen GL, Holme S. Bilateral epidural hematomas. Ugeskr Laeger 1991;154:20

11. Subrahmanian MV, Rajendraprasad GB, Dibbala BR. Bilateral extradural hematomas. Br J Surg 1975; 62: 397 400

12. Udoh DO. Bilateral post-traumatic acute extradural hematomas: A report of four cases and review of literature. Niger J Clin Pract 2012; 15: 104-107 